\title{
Evaluation of Web-based Simulations as Learning Media for Teaching Quantum Wave Packet Concept
}

\author{
T Aminoto*, F B Pujaningsih, S Purwaningsih, R Dani \\ Department of Physics Education, Jambi University, Indonesia
}

Received September 6, 2020; Revised November 11, 2020; Accepted November 19, 2020

\section{Cite This Paper in the following Citation Styles}

(a): [1] T Aminoto, F B Pujaningsih, S Purwaningsih, R Dani , "Evaluation of Web-based Simulations as Learning Media for Teaching Quantum Wave Packet Concept," Universal Journal of Educational Research, Vol. 8, No. 12A, pp. 7616 7624, 2020. DOI: 10.13189/ujer.2020.082547.

(b): T Aminoto, F B Pujaningsih, S Purwaningsih, R Dani (2020). Evaluation of Web-based Simulations as Learning Media for Teaching Quantum Wave Packet Concept. Universal Journal of Educational Research, 8(12A), 7616 - 7624. DOI: 10.13189/ujer.2020.082547.

Copyright $\odot 2020$ by authors, all rights reserved. Authors agree that this article remains permanently open access under the terms of the Creative Commons Attribution License 4.0 International License

\begin{abstract}
Quantum wave packet is one of the well-known topics which is difficult to the students because of its abstract, mathematical and complex characteristics. Web-based simulations, as learning media of quantum physics course, are widely available on the Internet, this research aimed to review and evaluate several versions of quantum wave-packet web-based simulations. This paper was part of the preliminary study in developing ICT-based quantum physics learning modules at Jambi University. It was found that there were 4 websites that provided a high-quality web-based simulation for teaching and learning of quantum wave packet. The simulations were evaluated based on the hierarchical framework and evaluation of educational software method including proposed additional criteria for more specific evaluation. The quantum wave-packet simulation of PhET version gets the highest score, followed by the Schroeder with a slightly different score, Quvis and Physlet version are in the lower position. However, in terms of convenience for users to run directly in the browser, the ease to perform modifications according to user needs, and having another supporting simulation, the Schroeder version is a better learning media. In addition, as the java platform often has compatible issues with many popular browsers, Schroeder version which is HTML-based simulation is more preferable. The performance highlights of each simulation and its specific comparison results are also discussed.
\end{abstract}

Keywords Quantum Wave Packet, Simulation, Learning Media, Evaluation

\section{Introduction}

Quantum physics is a unique theory of thinking about nature that is radically far different from classical physics theory. Besides using a high level of mathematics, the concept of quantum physics itself is seen as overly complex [1], abstract and difficult for students [2]. Inappropriate teaching practices, more emphasizing mathematical aspects, have caused problems and have been a matter of scientific debate for years [3]. Quantum physics learning is often faced with several challenges, e.g. the concept of uncertainty and super-position. This concept is counter-intuitive to the classical world view that is indeed familiar to most students. Another is the expectation value which is also an important concept in quantum mechanics, but many students encounter conceptual and procedural difficulties when determining it [4]. A good understanding of the concept of probability distribution in quantum physics is especially important to connect quantum formalism with measurement but students often have difficulties in understanding this concept in different representations [5][6]. The main problem in understanding quantum physics is the nature of quantum theory [7]. The difference between the conceptual nature of quantum mechanics and classical physics, which often leads to misconceptions, requires an appropriate teaching strategy [8]. Radical changes in learning strategies are needed [9], so that ways to trigger 
conceptual understanding increment must be investigated [11].

The evolution in time of quantum wave packet which is the focus of this study is part of those problems. It is difficult for students to master the concept of time dependent problem which is fundamental for the description of quantum systems [12]. It is why the developments in quantum physics learning currently emphasize more on visualization and conceptual understanding [14]. To help students in learning abstract and difficult concepts, there have been several simulations related to quantum wave packet phenomena available on the Internet: PhET (https://phet.colorado.edu), QuVis (https://www.st-andrews.ac.uk/physics/quvis), Physlet (https://www. compadre.org). All these simulations are mostly free but some must be accessed online because it cannot be downloaded. However, it is still difficult to find a research that evaluates and compares these web-based simulations especially in the context of searching the best learning media for teaching and learning of quantum wave packet concept. The result of online searching on the google scholar with keywords 'evaluation on quantum wave packet web-based simulations' was null.

A simulation can be evaluated based on its abilities and compared it to others. There are comprehensive lists of criteria for evaluating simulation software so that an appropriate selection process can be done by teachers who want to use them. In this study the hierarchical framework [19] and educational software evaluation method [16] are used to assess which simulation is the most appropriate.

\section{Simulations as Learning Media}

Simulation is a computer program that is designed to mimic a process or phenomenon that is usually carried out in a real laboratory. A simulation is also a tool for achieving high-quality learning by providing virtual equipment, algorithms, and other equipment in certain disciplines. As a result of the development of computer technology, virtual simulation has gradually become a widely applied topic in the field of science and technology education. At the same time, noting the extraordinary superiority of virtual simulation technology in its application to teaching practices, many schools, companies and research institutions at home and abroad have begun to pay attention to its development and application to teaching. At present, many virtual simulations and virtual teaching systems have been used in many tertiary institutions. As one of the most widely used simulation media applications, PhET (Physics Educational Technology) provides some interesting learning features for lecturers, individual activities and small groups [29]. This feature is specifically designed to support students in building a strong conceptual understanding of physics through exploration [20] and analysing the results of problem-solving activities [28]. Computer simulations assist students in building everyday understanding with underlying concepts, for example, the existence of physical models such as electric currents and magnetic fields that cannot be shown visually in physical laboratories.

The massive developments in quantum physics learning currently emphasize more on visualization and conceptual understanding [14]. For the abstract and confusing phenomenon or concept of quantum physics, a computer simulation program can be the right solution because of its ability to simulate the behaviour of quantum mechanical systems [21]. Computer simulations also have the advantage of being easier to use, and easily accessible at any time at any place according to the needs of its users [28]. Problems related to abstract and complex processes that require visualization can be assisted by a computer simulation as it can represent and visualise the phenomena that are complicated [27]. Thus, for solutions to such problems, a computer simulation can also be used as a pre-laboratory training if it is accompanied by theoretical background and some practical information about laboratory procedures and presents a holistic picture through visualization and simulation.

Virtual simulations provide opportunities for users to conduct investigations and experiments that are associated with experimental objects based on the user's skill level [31]. Virtual simulations can stimulate active involvement with the material and expose students to gain limited external experience in the classroom [30]. Virtual simulations offer quick access to experiments whereas in physical laboratories a lot of time is needed to prepare the equipment, and experiments cannot be repeated quickly. In virtual simulations, it can also add certain specific features that seem like real things like electric current flowing in a circuit [32].

\section{Research Methods}

This research is qualitative study which evaluates several web-based simulations of quantum wave-packet phenomena. Evaluation was conducted based on media and educational aspects using three methods. First, the hierarchical framework method, it consists of seven main indicators: vendors, models and inputs, execution, animation, output, user, testing and efficiency [19]. Since this method has many sub-criteria, only selected criteria are taken and adapted. Some selected criteria and its adaptations are presented in the Table 1. 
Table 1. Some listed criteria, adapted from hierarchical framework method

\begin{tabular}{|c|c|c|}
\hline Criteria & Hierarchical framework & adaptation \\
\hline documentation & $\begin{array}{c}\text {... a user manual, and } \\
\text { tutorials which can help } \\
\text { the user learn how to use } \\
\text { the packet ... }\end{array}$ & $\begin{array}{l}\text { learning material, } \\
\text { student's } \\
\text { worksheet }\end{array}$ \\
\hline support & $\begin{array}{c}\text {... training courses will } \\
\text { help the user to learn the } \\
\text { packet faster. Maintenance } \\
\text { and update of the } \\
\text { software ... }\end{array}$ & $\begin{array}{c}\text { provide email } \\
\text { contact, etc }\end{array}$ \\
\hline coding aspects & $\begin{array}{l}\text {...flexibility that allows the } \\
\text { user to enter the code... }\end{array}$ & $\begin{array}{l}\text { access to modify, } \\
\text { translate the } \\
\text { language }\end{array}$ \\
\hline Software class & ... a simulation language... & $\begin{array}{l}\text { platform: flash, } \\
\text { java, HTML }\end{array}$ \\
\hline
\end{tabular}

Second, evaluation for educational aspects is carried out by software analysis methods in education [7]. Third, the simulations are evaluated based on additional criteria which specifically assess the simulations according to their performance and compare them with others for the same topic.

\section{Results and Discussion}

Searching for quantum simulation providers or websites on the Internet was done by using Google search engine with the help of specific keywords. For the keyword "quantum physics simulation" only yielded one source of simulation: Quvis, categorized as interesting and having potential to be an option. With "quantum mechanics simulation" keyword, it also resulted in the same output. But, by adding the word "software", another interesting source of simulation that is https://physics.weber.edu/schroeder/software/ was appeared. It is rather surprising that from these three searches the well-known sources of quantum physics simulation such as PhET and Physlet, were not found. This indicates that searching the quantum physics simulations on the Internet is not as easy as the searchers think. It is quite difficult except we use many sets of different keywords. From the results of web-based simulations searching above, it is found that there are 4 websites which are listed in the Table 2 . These websites provide interesting simulations and have potential to be selected as the best choice of media to be used in quantum physics learning.

There are several research findings related to quantum physics learning with these simulation media. Students who are experimenting with PhET simulations with minimal guidance can explore the experiment of wave interference like how scientists explore a phenomenon. It is because the simulation has appropriate features which can be clicked and by frequently doing trial and error students can achieve the goals of the experiment. PhET is also well-known as a flexible simulation: allowing students to choose their learning patterns and paces. Furthermore, this type of inquiry is supported by simulation features such as concrete correlation to the real world, representations not available in the real world, analogies that help students make meaning, connect various representations and high levels of interactivity accompanied by feedback. These PhET structures enable students to ask questions and answer them in ways that might not be available in traditional educational media [20]. Many researches that have developed Quvis simulation media were conducted by Kohnle [13].

Quvis provides a group of interactive simulations that can be useful for all levels of the undergraduate curriculum. Each simulation uses a step-by-step investigation that clarifies the main points [13]. Some simulations allow students doing measurement of data to determine quantum-mechanical quantities experimentally. To be an independent teaching tool, it uses text explanation. Simulations and activities are continuously revised using many sources of feedback. To allow a greater focus on conceptual understanding, Quvis uses simple mathematics [14].

Physlet Simulation is an interactive simulation with more than 30 titles that are designed and ready to be used for teaching quantum physics. The material is arranged using standards that are easily understood with an interface designed using a pedagogical approach. The purpose of Physlet is to provide learning resources for the teaching of quantum physics so that it can increase students' motivation and activities through interactive approaches and visualizations. Physlets are also flexible to be adapted into various pedagogical strategies [33]. The last provider is Schroeder that provides some interesting computer simulations in quantum physics and also in other physics areas.

Table 2. Four interesting sources of quantum physics simulation providers

\begin{tabular}{cccccc}
\hline Source Address & Name & $\begin{array}{c}\text { Number of } \\
\text { simulations }\end{array}$ & Platform & Level & Language \\
\hline $\begin{array}{c}\text { http://phet.colorado.edu/en/simulations/category/phy } \\
\text { sics/quantum-phenomena }\end{array}$ & PhET & 20 & Java & $\begin{array}{c}\text { basic to } \\
\text { inter-mediate }\end{array}$ & multi \\
\hline $\begin{array}{c}\text { https://www.st-andrews.ac.uk/physics/quvis/de/inde } \\
\text { x-news.php }\end{array}$ & QuVis & 40 & $\begin{array}{c}\text { HTML } \\
\text { Flash }\end{array}$ & basic to high & $\begin{array}{c}\text { English } \\
\text { German }\end{array}$ \\
\hline https://www.compadre.org/PQP/quantum-theory/ & Physlet & 30 & Java & basic to high & English \\
\hline http://physics.weber.edu/schroeder/software/ & Schroeder & 12 & HTML & basic to high & English \\
\hline
\end{tabular}


The web-based simulations of quantum wave-packet that have been collected were evaluated in the several steps. First, the hierarchical framework method [19] is used to evaluate all versions of the obtained simulations using criteria based on Table 3 with scoring technique: if not available $=0$, if available: $1=$ bad, $2=$ enough, $3=$ good, 4 $=$ very good. The results of evaluation on the media aspect are presented in the following table:

Table 3. Evaluation of simulations based on hierarchical framework method

\begin{tabular}{ccccc}
\hline Criteria & PhET & QuVis & Physlet & Schroeder \\
\hline documentation & 2 & 4 & 4 & 2 \\
support & 3 & 3 & 3 & 2 \\
coding aspects & 2 & 2 & 2 & 2 \\
Reset capability & 3 & 3 & 3 & 3 \\
Start in non-empty & 3 & 3 & 3 & 3 \\
state & 3 & 3 & 3 & 3 \\
Speed control & 4 & 4 & 3 & 3 \\
Screen layout & 3 & 3 & 3 & 3 \\
Step function & 3 & 3 & 3 & 3 \\
Breakpoints & 4 & 3 & 3 & 0 \\
Backward clock & 4 & 4 & 2 & 2 \\
Delivery & 3 & 3 & 3 & 3 \\
Orientation & 4 & 4 & 4 & 4 \\
Financial (if free, & & & & 4 \\
score=4) & 3 & 4 & 2 & 38 \\
Software class & 44 & 46 & 41 &
\end{tabular}

Based on the Table 3, the version of Quvis simulation obtained the highest rating score. The advantage of Quvis over the PhET version lies in the point of better documentation which is more systematic and complete. In terms of software class aspect, all the simulations are available in the HTML platform. In addition, the above assessment results have almost the same result for almost all the titles in each version, this is because for the same version its grand design is almost the same.

The next evaluation more focuses on educational aspects. This method evaluates the capability of web-simulations on the concept of wave packets based on a questionnaire for educational software evaluation [16]. The evaluation results are presented in Table 4.

In evaluating several simulation versions for the same topic, it is not enough to only use the general evaluation criteria above but it requires specific criteria to obtain more accurate comparison results. There are several specific criteria which are not listed in the above criteria that need to be used as consideration of the more specific aspects in the educational context [15]. This idea also supported by a finding that the simulations' design features and use will determine the degree of its effectiveness [23]. The proposed of specific criteria for a simulation on the topic of time-dependent wave packet are listed in the Table 5 including the evaluation results.

Table 4. Evaluation results for 4 simulation versions based on educational aspect criteria

\begin{tabular}{|c|c|c|c|c|}
\hline \multirow{2}{*}{ Criteria } & \multicolumn{4}{|c|}{ Simulation version } \\
\hline & PhET & QuVis & Physlet & Schroeder \\
\hline Is the software consistent with the curriculum and learning outcomes? & 4 & 2 & 3 & 4 \\
\hline Does the software offer options and controls? & 4 & 3 & 3 & 4 \\
\hline Does the software provide the right variety of media and activities? & 4 & 3 & 3 & 4 \\
\hline Does the software provide positive-formative feedback, and achievements? & 1 & 2 & 2 & 1 \\
\hline Is the software challenging? & 4 & 2 & 2 & 4 \\
\hline Does the software have high-quality technical components? & 4 & 2 & 2 & 4 \\
\hline Does the software provide opportunities for practice and review? & 3 & 3 & 3 & 3 \\
\hline Does the software present the material in a fun and interesting way? & 2 & 2 & 3 & 2 \\
\hline What is interactive software? & 4 & 2 & 2 & 4 \\
\hline Will the software allow social interaction? & 1 & 1 & 1 & 1 \\
\hline Will the software present learning in an authentic and relevant context? & 3 & 2 & 3 & 3 \\
\hline Is the software accessible to students? & 4 & 4 & 4 & 4 \\
\hline Total Score & 38 & 28 & 31 & 38 \\
\hline
\end{tabular}

Table 5. Additional criteria for more detail evaluation result

\begin{tabular}{|c|c|c|c|c|}
\hline \multirow{2}{*}{ Specific criteria } & \multicolumn{4}{|c|}{ Simulation version } \\
\hline & PhET & QuVis & Physlet & Schroeder \\
\hline Can the simulation show the real and imaginary part of the wave? & 4 & 0 & 0 & 4 \\
\hline Can the user choose the real or imaginary part? & 4 & 0 & 0 & 0 \\
\hline Is there a choice to adjust the packet wave width? & 4 & 0 & 0 & 4 \\
\hline Is there a choice of wave packet height adjustment? & 4 & 0 & 0 & 4 \\
\hline Is the size of wave easy to be observed? & 2 & 4 & 3 & 4 \\
\hline Whether simulation is linked to Heisenberg's concept of uncertainty? & 0 & 4 & 0 & 0 \\
\hline Is there a specific instruction/hint? & 1 & 2 & 4 & 4 \\
\hline Possibility the user can modify the simulation & 2 & 3 & 1 & 4 \\
\hline Total score & 21 & 13 & 8 & 24 \\
\hline
\end{tabular}


To get an overall result, the evaluation results above can be accumulated and presented as follow:

Table 6. The cumulative score of evaluation

\begin{tabular}{ccccc}
\hline $\begin{array}{c}\text { Type of } \\
\text { evaluation }\end{array}$ & PhET & QuVis & Physlet & Schroeder \\
\hline $\begin{array}{c}\text { Hierarchical } \\
\text { framework }\end{array}$ & 44 & 46 & 41 & 38 \\
$\begin{array}{c}\text { Educational } \\
\text { software } \\
\text { Additional } \\
\text { criteria }\end{array}$ & 38 & 28 & 31 & 38 \\
\hline Total score & 103 & 86 & 72 & 100 \\
\hline Average score & 34,3 & 28,6 & 24 & 33,3 \\
\hline
\end{tabular}

From the Table 6, it can be seen that the PhET version gets the highest score. However, it has a slightly different score with Schroeder version. Quvis and Physlet version are far under others' versions. In addition, this result is in line with a study exploring the users' interest in PhET simulation using Google Trends and Web analytics, it shows that it is one of the most well-known scientific web-based simulation resources which has been escalating since 2005 [26]. Although this study did not mention specifically in what specific titles they were and it indicated that all PhET simulations have the same grand design and quality.

According to Table 5, the evaluation results based on the proposed specific criteria, in this section the specific performance highlights of each simulation are presented. This will give more detail information regarding the evaluation of the 4-simulation version above.

In the PhET version, Figure 1, the wave packet can propagate and change its shape with time. The width is getting wider and its amplitude is getting shorter. This change is most likely very confusing for students because it is known that the wave packet in that space is free from any external potential or mediums (free particles). Therefore, it should not experience amplitude changes. In fact, this confusing phenomenon is related to the conceptual differences in quantum mechanics and classical physics, which often lead to misconceptions. Therefore, it does require an appropriate teaching strategy [15]. In addition, it is known that the waves that propagate are non-dispersible ( $\omega$ is linear concerning $\mathrm{k}$ so that the velocity of the wave group is equal to the phase velocity) and can undergo dispersion ( $\mathrm{k}$ is not linear, the velocity of the wave group is not the same as the phase velocity) due to the medium.

Besides being able to display real (red) and imaginary (blue) parts separately, this simulation is also capable of displaying wave packets that propagate with their phase display (which is colourful according to its phase) either simultaneously or separately. Another advantage is that the width of the initial wave packet can be increased or decreased which help the users to better observe its effect.

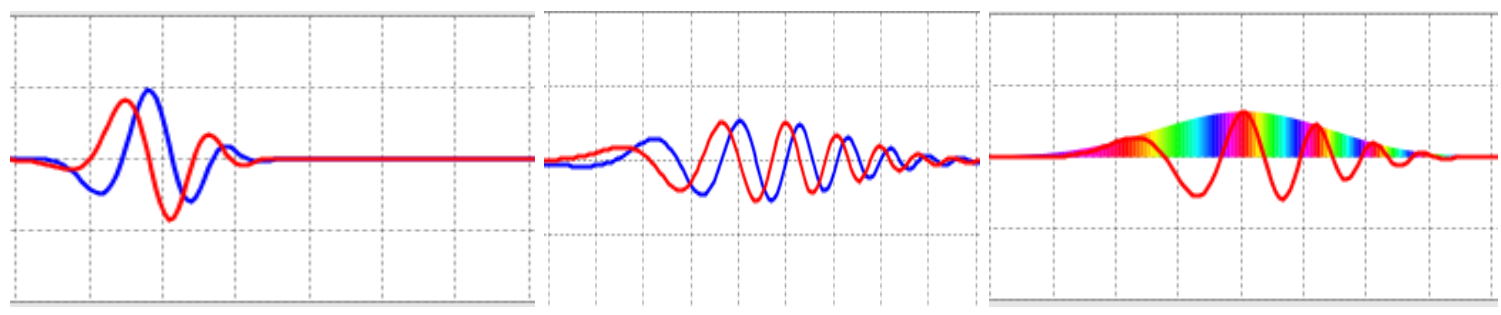

Figure 1. Wave packet propagation in PhET simulation
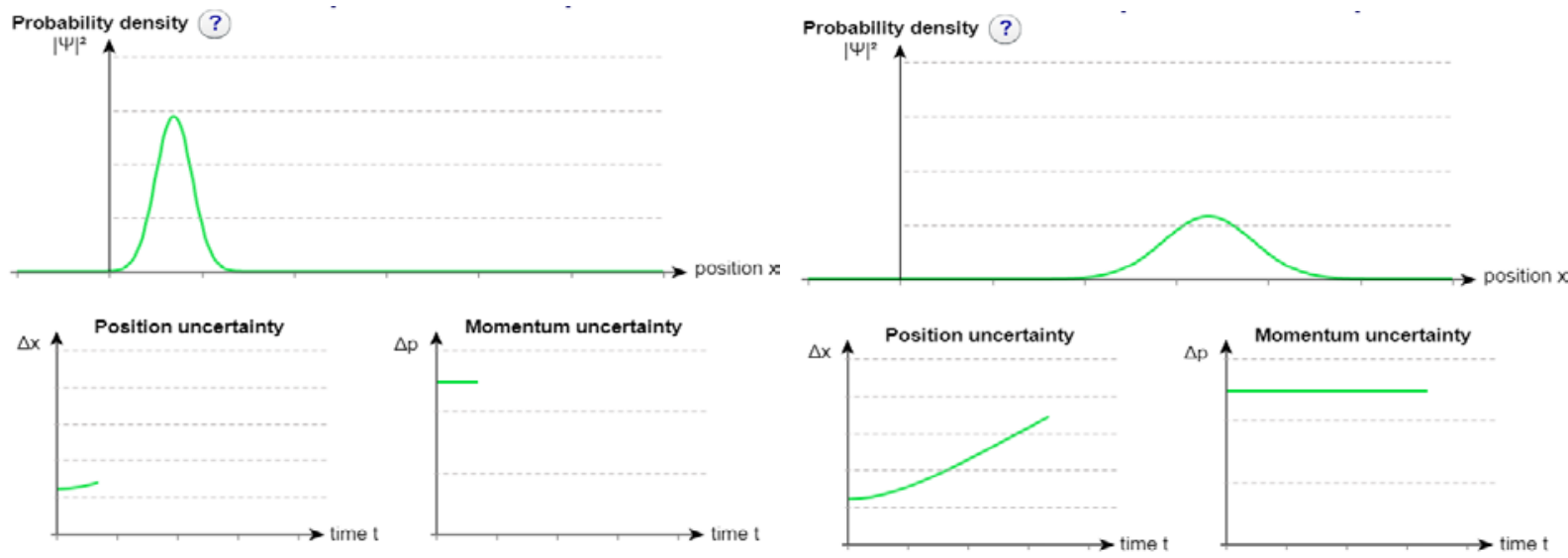

Figure 2. Wave packet propagation in Quvis simulation 

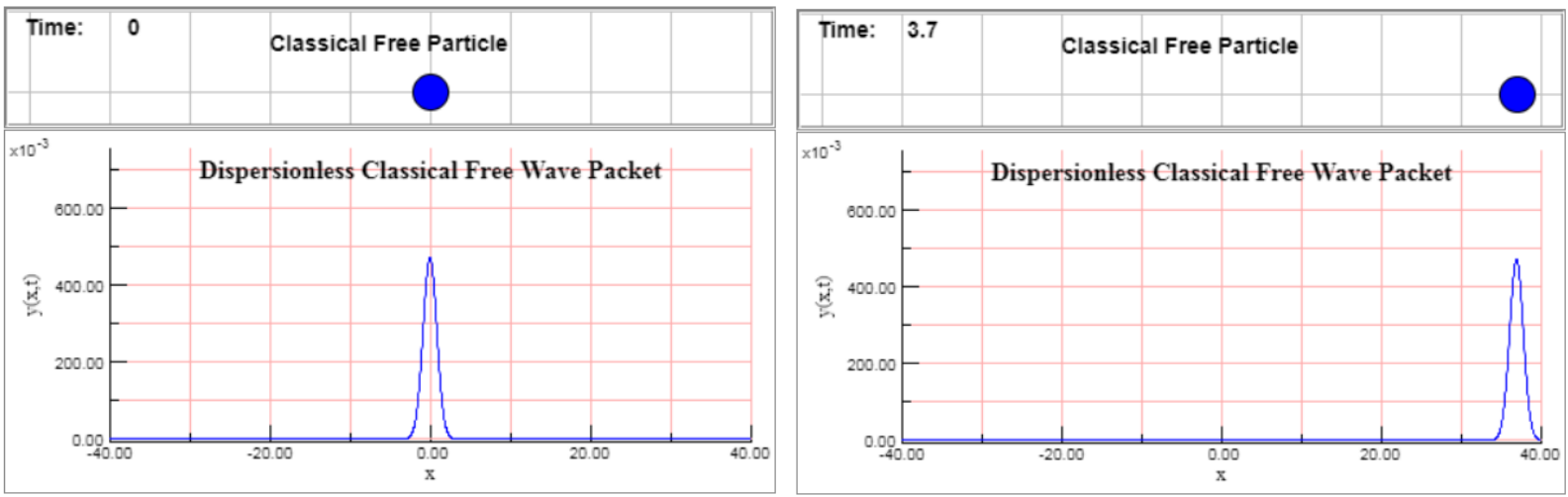

Figure 3. Wave packet propagation in Physlet simulation
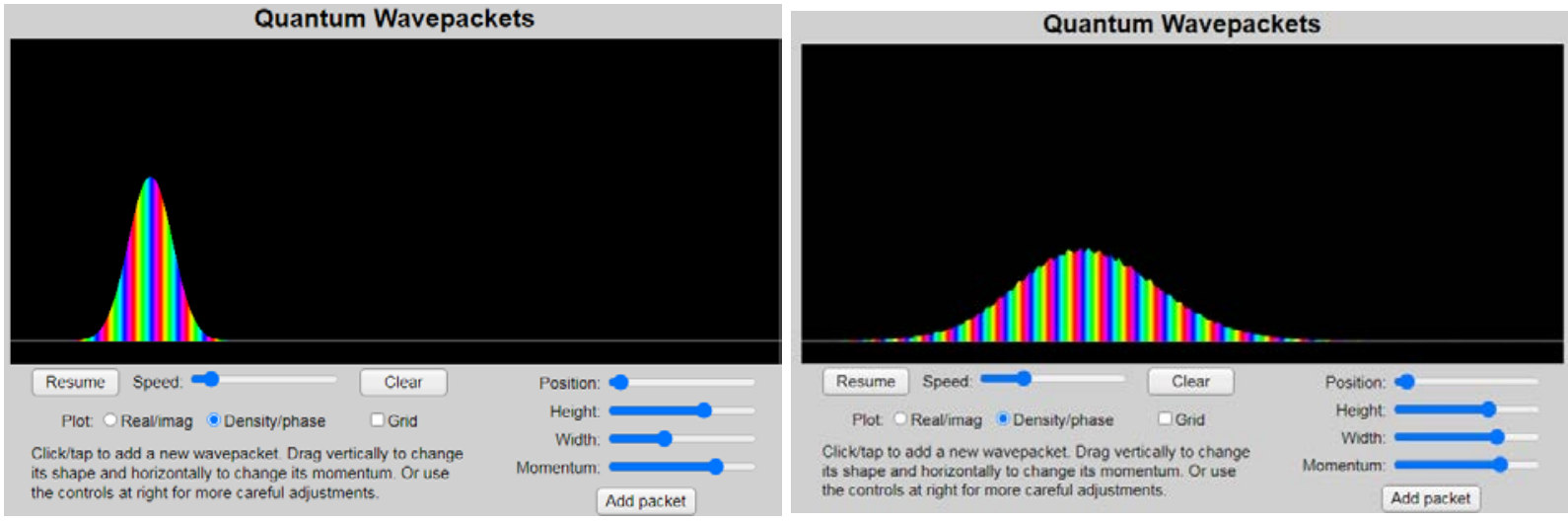

Figure 4. Wave packet propagation in Schroeder simulation

On the other hand, in the Quvis version, in the figure 2, it only shows the probability density, $|\Psi|^{2}$. Another difference is that the wave packet is connected to Heisenberg's uncertainty principle with features that the initial values of position and momentum the uncertainty can be adjusted, and the upward trend can be seen on the chart. Therefore, this simulation visualizes time dependent wave packet and its relationship with the uncertainty concept between the momentum and position according to Heisenberg's uncertainty principle. But it is not quite suitable as learning media for in-depth study of the characteristics of a wave packet. A study mentioned that not all simulations are equally effective in all situations [18].

In the Physlet version, Figure 3, the wave packet is visualized in the simplest way among other simulation versions. It can be seen that the wave-packet propagates in dispersion-less with very simple view. However, the existence of a classical particle that moves over the wave packet as an analogy for the nature of abstract quantum particles is quite helpful for students who are beginners with the wave nature of quantum particles.

Compared to PhET version, Schroeder version only focuses on one topic which is the characteristic of the wave packet, Figure 4, while in the PhET version on the same screen there are several different topics of simulation options, such as reflection and transmission experienced by the wave packet, and also other types of wave, with adjustable potential barriers and its physical models. Therefore, in terms of focus, the Schroeder simulation version is considered as a better to be used as a medium for teaching quantum wave packet characteristics of its time-related behaviours. In addition, using a better simulation-based media will increase students' motivation and understanding, and also lead to a maximal learning gain according to the learning objectives [12].

All the simulations above do not provide an adequately hand-on description about the causes of the unique phenomenon of why the wave packet is changing its shape during propagation even though the potential or external force does not exist in the system. Regarding this, the online and complete explanation was found on the other websites which more focus on the mathematical aspect of the wave packet. It is stated that the wave packet naturally expands because it contains or is formed of many wave components with different momentum and therefore different speeds. All of this is a direct result of the time change aspect in the (time-dependent Gaussian) equation of the free particle wave packet. A clearer explanation is to review the mathematical equation of the wave at $t=0$ and find the solution at time t. From this, it will be obtained that the change in the width of the wave packet is influenced by the relationship $\omega$ to $\mathrm{k}$. For photons, $\mathrm{E}=\mathrm{p} \mathrm{c}$ and $\mathrm{p}=\hbar \mathrm{k}$ then $\hbar \omega=\hbar \mathrm{kc}$ and $\omega=\mathrm{k} \mathrm{c}(\omega$ linear to $\mathrm{k}$ 
does not experience dispersion) while for electrons $E=p^{2}$ / $2 \mathrm{~m}$ so that $\omega=\hbar^{2} \mathrm{k}^{2} / 2 \mathrm{~m}(\omega$ is not linear to $\mathrm{k}$ so it experiences dispersion). Wave packets that are very localized (very narrow) in space will propagate faster than wave packets that are originally wider in shape [24][22].

The absence of a detailed explanation of the explanations, procedures and simulation results above could be related to other research findings. If all instruction and explanation are given, it is likely that students can complete experiments without having to think to understand the equations and concepts of physics. This is because they can simply follow the instructions without having to think and understand them. These findings suggest that for teaching a physics experiment course, combining multiple laboratory activities with results that students do not know yet, will have a significant impact on students' understanding of the experiment. This is also an important approach to develop students' scientific knowledge [10].

In the Schroeder version, a simulation that has closely relation and supports the existence of wave packet simulations is provided, namely the wave builder simulation (Figure 5) which visualizes the formation of the wave packet. Therefore, this co-simulation is the answer to the critical student question of how the wave packet is formed. A study stated that the inadequate computer technology support in hardware or software, as one of contextual factors, will affect the use of computer technology [25]. This statement is in line with the need of other supporting simulations for the wave packet which is considerably needed as described in this section.

The wave builder will help the students in understanding the wave packet formation. It is done by the fact that a wave packet is built by summing many waves with different amplitude, wavelength and phase. To do this, students can follow the clue that is given by the simulation in wave packet building process. Considering this, it is worth to say that in the case that a better simulation needs to have other supporting simulations which are at least as an explanation or a prerequisite for the simulation. In this aspect, the Schroeder version is superior to the PhET version.

In addition to java platform having many advantages, PhET simulations are mostly in java-platform which cannot be played directly from the browsers, and java-based simulations often have problems of not working in many students' laptop as it needs an additional installation procedure which is not always easy to be done by the users. For simulations with the HTML platform, mostly they do not have such problems. The HTML simulation platform is a better platform that needs to be used in the future because of its simplicity: directly running on the browser. Moreover, as java-based simulation is also vulnerable to cyber-attacks and is no longer compatible with secure browsers, recently many web-based simulations are being moved to HTML5 framework [17]. These findings suggest that HTML-based simulation is currently the best choice of simulation platform for reducing technical problems faced by the users.

One of the possible disfavours of this sort of software evaluation research is that simulations may change year by year. As this evaluation was done at the beginning of 2020, educators or potentially understudies at a specific year will watch a somewhat adjusted or even various re-enactments from those in the earlier years. At that point the usefulness for their instructing and learning changes. It is additionally liable to happen that the users may not discover the referred to adaptation on a similar site. The creators ought to portray at any rate when this examination was done or which variant of every reproduction was assessed.

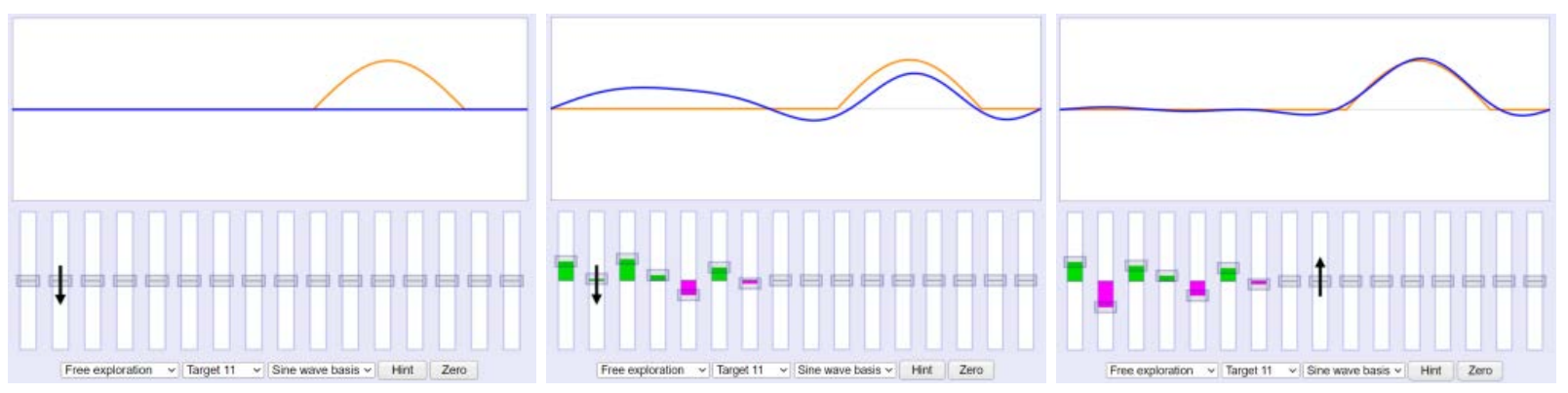

Figure 5. The use of wave builder to visualize a wave packet formation 


\section{Conclusions}

The searching of high-quality web-based simulations as learning media of quantum wave packet in teaching quantum physics has been conducted. The results from 3 method of evaluation above show that the quantum wave-packet simulation of PhET version gets the highest score, followed by the Schroeder with a slightly different score, Quvis and Physlet version are in the lower position. However, in terms of convenience for users to run directly in the browser, the ease to perform modifications according to user needs, and having another supporting simulation, the Schroeder version is a better learning media. In addition, as the java platform is vulnerable to cyber-attacks and often has compatible issues with many popular browsers, Schroeder version which is HTML-based simulation is more preferable than PhET. To achieve a maximum result of implementing them to the classroom activity, it is necessary to make a combination of several versions of the simulations proportionally depending on the users' need and convenience.

\section{Acknowledgement}

This research was funded by the Faculty of Education and Teacher Training - Jambi University PNBP funding scheme 2020.

\section{REFERENCES}

[1] Kohnle, A., Research-based interactive simulations to support quantum mechanics learning and teaching. in C Fazio \& R M S Mineo (eds), Teaching/Learning Physics: Integrating Research into Practice: Proceedings of the GIREP-MPTL, 2015.

[2] Thompson, J. D., Modir, B., \& Sayre, E. C., Algorithmic, conceptual, and physical thinking: a framework for understanding student difficulties in quantum mechanics. In Proceedings of the International Conference of the Learning Sciences, 2016.

[3] Johnston, I. D., Crawford, K., \& Fletcher, P. R., Student difficulties in learning quantum mechanics. International Journal of Science Education, 20(4), 1998, pp 427-446.

[4] Junglas, P., Simulation programs for teaching quantum mechanics. Conference Paper Department of Mechanical Engineering. Germany, 2010.

[5] Marshman, E., \& Singh, C., Investigating and improving student understanding of the probability distributions for measuring physical observables in quantum mechanics. European Journal of Physics, 38(2), 2017.

[6] Singh, C. \& Marshman, E., Student difficulties with determining expectation values in quantum mechanics. Department of Physics and Astronomy. University of
Pittsburgh: Pittsburgh, 2017.

[7] Lautesse, P., Valls, A. V., Ferlin, F., Héraud, J. L., \& Chabot, H., Teaching quantum physics in an upper secondary school in France. Science \& Education, 24(7-8), 2015, pp 937-955.

[8] Krijtenburg-Lewerissa, K., Pol, H. J., Brinkman, A., \& Van Joolingen, W. R., Insights into teaching quantum mechanics in secondary and lower undergraduate education. Physical review physics education research, 13(1), 2017

[9] Kalkanis, G., Hadzidaki, P., \& Stavrou, D., An instructional model for a radical conceptual change towards quantum mechanics concepts. Science education, 87(2), 2003, pp 257-280.

[10] Dehui Hu, Benjamin M. Zwickl, Bethany R. Wilcox, and H. J. Lewandowski, Qualitative investigation of students' views about experimental physics, Phys. Rev. Phys. Educ. Res. 13(2), 2017.

[11] Chi, M. T. H., In Handbook of Research on Conceptual Change (edited by S. Vosniadou). Routledge: New York, 2008, pp 61-82.

[12] Passante, G., \& Kohnle, A., Enhancing student visual understanding of the time evolution of quantum systems. Physical Review Physics Education Research, 15(1), 2019.

[13] Kohnle, A. Cassettari, D. Edwards, T., A New Multimedia Resource For Teaching Quantum Mechanics Concepts. American Journal of Physics (2), 2012, pp 148-153.

[14] Kohnle, A., Bozhinova, I., Browne, D., Everitt, M., Fomins, A., Kok, P., ... \& Swinbank, E., A new introductory quantum mechanics curriculum. European Journal of Physics, 35(1), 2013.

[15] Imlig-Iten, Nina \& Petko, Dominik., Comparing Serious Games and Educational Simulations: Effects on Enjoyment, Deep Thinking, Interest and Cognitive Learning Gains. Simulation \& Gaming, 49, 2018, pp 401-422. DOI:10. $1177 / 1046878118779088$.

[16] Goyne, J., McDonough, S., \& Padgett, D., Practical Guidelines for Evaluating Educational Software. The Clearing House, 73(6), 2000, pp 345-348.

[17] Dixit, A., Katoch, S., Spanias, P., Banavar, M., Song, H., \& Spanias, A., Development of signal processing online labs using HTML5 and mobile platforms. In 2017 IEEE Frontiers in Education Conference (FIE), 2017, pp 1-5.

[18] Mešić, Vanes \& Dervić, Dževdeta \& Gazibegović-Busuladž ić, Azra \& Salibašic, D. \& Erceg, N., Comparing the impact of dynamic and static media on students' learning of one-dimensional kinematics, 11, 2015, pp 1119-1140. DOI:10. 12973/eurasia.2015.1385a.

[19] Nikoukaran, J. Hlupic, V. Paul, R.J., A hierarchical framework for evaluating simulation software. Journal of Simulation Practice and Theory (7), 1999, pp 219-231.

[20] Podolefsky, N. S., Perkins, K. K., \& Adams, W. K., Factors promoting engaged exploration with computer simulations. Phys. Rev. ST Phys. Educ. Res. 6, 2010.

[21] Shah, Y. A., Mir, I. A., \& Rathea, U. M., Quantum Mechanics Analysis: Modeling and Simulation of some simple systems. Int. J. Math. Sci. Comput (IJMSC), 2(1), 
2016, pp 23-40.

[22] German Research School for Simulation Sciences and RWTH Aachen University, Applied Quantum Mechanics, https://www.cond-mat.de/teaching/QM/JSim/wpack.html. (accessed June 3, 2020).

[23] Smetana, L. K., \& Bell, R. L., Computer simulations to support science instruction and learning: A critical review of the literature. International Journal of Science Education, 34(9), 2012, pp 1337-1370.

[24] Branson, J., Time Development of a Gaussian Wave Packet. https://quantummechanics.ucsd.edu/ph130a/130_notes /node83.html. (accesed June 1, 2020).

[25] Gilakjani, A. P., Factors Contributing to Teachers' Use of Computer Technology in the Classroom. Universal Journal of Educational Research, 1(3), 2013, pp 262-267.

[26] Zhang, M., Who are interested in online science simulations? Tracking a trend of digital divide in Internet use. Computers \& Education, 76, 2014, pp 205-214.

[27] Ghergulescu, I., Lynch, T., Bratu, M., Moldovan, A., Muntean, C. H., \& Muntean, G. M., STEM Education with atomic structure virtual lab for learners with special education needs. International Conference on Education and New Learning Technologies, 2018.

[28] Ceberio, M., Almudi, J.S., \& Franco, A., Design and Application of Interactive Simulations in Problem Solving in University-Level Physics Education. Journal Science Education and Technology, 2016.

[29] Wieman, C.E., Adam, W. K., Loeblin, P., \& Perkins, K. K., Teaching Physics Using Phet Simulations. The Physics Teacher, 8, 2010, pp 225-227.

[30] Zimmermann, L.K., Using A Virtual Simulation Program To Teach Child Development, College Teaching, 61/4, 2013, pp 138-142.

[31] Karagoz, O., \& Ozdener, N., Evaluation Of The Usability Different Virtual Lab Software Used In Physics Course. Bulgarian Journal of Science and Education Policy, 4/2, 2010, pp 216-235.

[32] Zacharia, C.Z., \& Jong, D.T., One Specific Advantage For Virtual Laboratories That May Support The Acquisition Of Conceptual Knowledge Is That Reality Can Be Adapted To Serve The Learning Process. Reality Can Be Simplified By Taking Out Details. Cognition and Instruction, 32/2, 2014, pp 101-158.

[33] Belloni, M., Christian, W., \& Cox, A.J., Physlet Quantum Physics: An Interactive Introduction, Pearson, 2005. 